\title{
SUBJETIVIDADE JURÍDICA E DIREITO DOS ANIMAIS: UM CASO PARA A EXTEMPORANEIDADE
}

\author{
LEGAL SUBJECTIVITY AND ANIMAL RIGHTS: A CASE FOR THE \\ EXTEMPORANEOUS
}

Recebido: 18.02.2020

Aprovado: 19.05.2020

\author{
Leonardo Monteiro Crespo De Almeida \\ Doutor e Mestre em Direito pela UFPE. Bacharel \\ em Filosofia pela UFPE. \\ E-MAIL: leonardoalmeida326@gmail.com \\ LATTES: http:/ /lattes.cnpq.br/3918991603659430 \\ ORCID: http:/ / orcid.org/0000-0001-5742-3344
}

\begin{abstract}
RESUMO: O presente artigo pretende realizar uma sucinta investigação acerca da subjetividade jurídica no contexto dos direitos dos animais. Detêm-se em expor alguns obstáculos para a formulação de uma noção de subjetividade jurídica animal a partir de certos pressupostos teóricos da teoria do direito contemporânea. Por isso propõe uma noção extemporânea, deslocada, de subjetividade: uma que, não necessariamente reconhecida pelos ordenamentos jurídicos ou teorias do direito vigentes, serve como fator problematizador de suas práticas, revelando-lhe os pontos cegos e questionando as suas operações: o que essa forma de subjetividade enfatiza e traz é a abertura ao outro, alteridade. A questão dos animais surge, neste horizonte, como vereda que leva ao questionamento de noções fundamentais da teoria do direito tradicional: concebe a subjetividade jurídica como agência humana e o exercício do direito como representação como resquícios de um humanismo que dificulta pensar o não-humano no direito.
\end{abstract}

PALAVRAS-CHAVE: Subjetividade; Desconstrução; Pós-Humanismo.

ABSTRACT: This present article intends to develop a brief investigation regarding legal subjectivity within the context of animal rights. One of its main concerns is to expose some obstructions to an animal legal subjectivity within the current legal theory and its premises. The article proposes a different notion of subjectivity, an extemporaneous one: this subjectivity cannot be found in contemporary legal order or its theoretical framework since it has a virtual reality, not an actual one. This subjectivity opens the legal domain to the alter and its alterity. The question of the animal and its legal subjectivity is taken as a theoretical path to question fundamental notions of traditional legal theory: the article conceives legal subjectivity as human agency and the exercise of rights as representation as traces of a humanism that imposes significant difficulties to think the non-human within the law.

KEYWORDS: Subjectivity; Deconstruction; Post-Humanism.

SUMÁRIO: 1 Introdução 2 As ambivalências do sujeito de direito: a subjetividade como construção discursiva e tecnologia 3 Extemporaneidade e subjetividade jurídica desumanizada: o animal para além da racionalidade jurídica operacional 4 Redefinindo a 
questão: o animal através da subjetividade jurídica extemporânea 5 Conclusão 6 Referências 7 Notas de referência

\section{Introdução}

No desenvolvimento do direito de moderno, a subjetividade jurídica se constitui em uma zona de problematização e contestação. Examiná-la envolve colocar em questão, direta ou indiretamente, as condições pelas quais a um ente pode exercer direitos e se submeter a deveres juridicamente constituídos: encontrar-se excluído dessa esfera significa também não ser reconhecido por um sistema normativo protegeria as suas prerrogativas existenciais. Fora do universo simbólico do jurídico, resta apenas a materialidade de corpos completamente disponíveis.

Mesmo uma análise histórica corriqueira de algumas das democracias liberais contemporâneas mostrara, no entanto, que a subjetividade jurídica traz consigo uma complexa e imprevisível dinâmica de aquisição e restrição de prerrogativas jurídicas. O que outrora carecia de representação e de importância à luz dos ordenamentos jurídicos e das circunstâncias políticas que Ihes acompanham passa desfrutar de protagonismo e relevância. Outros grupos, porém, enxergam com ansiedade uma contínua erosão dos seus direitos e garantias há muito conquistadas através da luta política. Interrogar a subjetividade jurídica, portanto, implica colocar em questão as condições de representação pelas quais alguém pode vir a formular uma demanda que seja também passível de aceitação jurídica.

A questão do animal eleva o nível de complexidade ao colocar em questão também o resíduo antropocêntrico que revestiria a ideia de subjetividade jurídica. Neste ponto, a doutrina e a teoria do direito acolhem certas exceções: ainda que uma empresa não seja um ser humano, ela adquire uma personalidade e responde em juízo na forma de pessoa jurídica. Embora a noção ainda remeta a um referencial humano (a empresa compreendida como um ente coletivo de pessoas físicas, por exemplo), a distinção entre pessoa física e jurídica é suficiente para mostrar que, em um nível muito básico e corriqueiro, a subjetividade jurídica possui mais desdobramentos e uma plasticidade maior do que, a princípio, ela apresenta.

Pensar o animal no horizonte da teoria do direito implica conceber os limites da subjetividade jurídica e as condições para a sua demarcação. É preciso averiguar se as mencionadas transformações sociopolíticas são capazes de subverter o núcleo essencial do sujeito de direito, precisamente aquelas qualidades e capacidades que vão separá-lo dos demais entes no mundo - ou mesmo se existiria um tal núcleo.

A hipótese de pesquisa deste trabalho consiste em sustentar que o conceito de subjetividade jurídica traz consigo um potencial que jamais se deixa exaurir nas formas contemporâneas de sujeito de direito, que a pesquisa nomeia como formas atuais de subjetividade. Justaposto a essas formas, existiriam outras que, embora tão reais quanto as outras, ainda não foram atualizadas: não integram ainda nem a estrutura normativa do direito positivo, nem as discussões jurisprudenciais.

O propósito teórico desta hipótese reside em destacar que o vazio de conteúdo presente nas categorias do direito positivo pode ser concebido em termos de potencialidades ainda não cultivadas. São essas potencialidades que forneceriam os elementos para se pensar uma subjetividade jurídica deslocada do presente estado das coisas, uma subjetividade que, não estando devidamente ajustada aos princípios e requisitos legais e doutrinários que organizam um 
determinado campo, é capaz de problematizá-lo, confrontando os seus limites ao mesmo tempo em que propõe linhas de experimentação para a atividade doutrinária.

Os direitos dos animais constituem um campo de investigação teórica em que essas questões podem ser colocadas com segurança. A ontologia jurídica subjacente às atuais configurações da subjetividade jurídica ainda resiste a situar de forma pontual uma subjetividade animal ao invés de toma-la como objeto de proteção jurídica através do humano e pelo humano. Uma proteção que não toma como referência principal aquele que será protegido, mas um terceiro, seja na forma de sociedade ou das pessoas que Ihe são circundantes, está fadada a ser contornada quando for conveniente.

A estrutura desta pesquisa obedece a seguinte ordem. Na primeira parte, recorrendo principalmente às reflexões de Costas Douzinas e Peter Fitzpatrick acerca do sujeito de direito, busca-se esclarecer a relação dual entre autonomia e subordinação que ele, o sujeito, mantém com o poder soberano. O objetivo é destacar a relação paradoxal que existe na formação do sujeito de direito e de que maneira o mesmo é atravessado por um vazio constitutivo. Na leitura proposta por esta pesquisa, esse vazio não se estabelece como uma ausência estritamente negativa, uma "falta de", mas como um campo de possibilidades que não tem como ser integralmente assimilado nas manifestações atuais da subjetividade jurídica. Por isso essa pesquisa vai se referir à subjetividade jurídica como ontologicamente contingente, ou seja, os mecanismos que confluem para a sua produção são circunstanciais ao invés de necessários.

Uma vez estabelecido o caráter ontologicamente contingente da subjetividade jurídica, a segunda seção tratará de pensar o animal neste panorama, o que exige pensar o lugar do animal no âmbito da ontologia jurídica. O objetivo desta seção é, porém, mais modesto: tendo como foco as reflexões de Cary Wolfe, pretende-se indagar o que acontece e que tipo de relação pode ser constituída com o não-humano. Dessa ponderação surge uma outra e que, para os propósitos desta pesquisa, é igualmente relevante: quais são os pressupostos para se pensar uma ontologia jurídica na qual a distinção entre o humano e o não-humano, no que concerne à subjetividade, seja factível?

Por fim, a terceira parte do artigo ressalta que a extemporaneidade de uma subjetividade não-humana, ou seja, a maneira pela qual ela não se insere nas atuais estruturas normativas do direito, é um excesso que põe em questão os limites constitutivos dessas mesmas estruturas. É através desse excesso, que foge à assimilação de qualquer estrutura normativa, que ontologia política e subjetividade jurídica se conectam em torno dos direitos dos animais.

A pesquisa recorreu a uma revisão de literatura tendo como eixo fundamental a necessidade de se pensar a inserção dos animais no âmbito jurídico e o próprio conceito de subjetividade jurídica. A revisão abrange, para além de Wolfe e MacLean, certas indagações teóricas trazidas por Jacques Derrida e Niklas Luhmann no tocante à abertura do jurídico ao seu exterior e à redefinição constante de suas próprias atividades. A pesquisa enxerga tanto na desconstrução quanto na teoria dos sistemas abordagens teóricas capazes de transpor, no que se refere à subjetividade, a divisão entre humano/não-humano no âmbito jurídico.

\section{As ambivalências do sujeito de direito: a subjetividade como construção discursiva e tecnologia}

Antes de se iniciar uma investigação mais específica no domínio jurídico, cabe observar que a questão do animal e sua relação com a subjetividade moderna emerge, no século vinte, através de uma série de passos teóricos independentes que, no fundo, convergem para um panorama em que se faz importante, para não dizer indispensável, repensar a separação entre animal/humano na filosofia, na política e também no direito. 
O primeiro grande golpe pode remontar à chamada crise do humanismo ocidental, e que se expressa no questionamento direto do ser humano como formador da história e das circunstâncias materiais em que ela se desdobra ao invés de ser por ela constituído. Louis Althusser desenvolve a sua posição através de uma crítica decisiva ao humanismo marxista. $O$ discurso científico e a epistemologia moderna que lhe caracteriza são historicizados por Michel Foucault, confrontando o idealismo subjacente ao sujeito do conhecimento e de seu privilégio epistemológico.

Uma definição básica de humanismo seria a seguinte: trata-se de um conjunto de filosofias que sustentam a dignidade e o valor de todas as pessoas tendo como base a habilidade de que possuem para determinar o que é certo e o que é errado tendo como referência qualidades humanas tidas como universais, a exemplo da racionalidade e da linguagem. Embora existam várias concepções distintas do humanismo, o seu núcleo reside em um comprometimento em se buscar a verdade e a moralidade através de meios que sustentam os interesses humanos. Ao focar a capacidade de autodeterminação, o humanismo rejeita a validade de justificações transcendentes, como a fé, o supernatural ou a fundamentação divina dos textos tradicionais. A moralidade universal do humanismo existe a partir da condição humana e em função dela.

O segundo grande golpe reside na ascensão dos paradigmas teóricos transdisciplinares, como a cibernética, a teoria dos sistemas, a teoria do caos, os estudos sobre animais, que já não recorrem ao humano como princípio explicativo ou como fundamento: nenhum desses campos se constitui em torno do humano, concebendo-o como um eixo privilegiado por meio do qual determinada área ou grupo de objetos pode ser investigado. Acrescente-se a isso também a reavaliação do animal em outras áreas fora das humanidades, reavaliação esta que faz surgir novos desafios e indagações para a forma usual como as ciências humanas tendem a abordar esta temática. Cary Wolfe escreve:

O segundo fator é uma realidade a que eu já aludi, ainda que sucintamente: a mudança radical do lugar do animal em áreas situadas fora das humanidades. De fato, as humanidades, na minha perspectiva, estão agora lutando para acompanhar a reavaliação radical do status dos animais não humanas que ocorrera na sociedade. Uma considerável explosão de trabalhos em áreas como etiologia cognitiva e ecologia de campo tem questionado a nossa habilidade de usar as velhas pinças do antropocentrismo (linguagem, ferramentas, comportamento cultural herdado, dentre outros) para nos separar de uma vez por todas dos animais, já que experimentos na linguagem e na cognição com grandes gorilas e animais marinhos, e estudos de campo de comportamentos culturais e sociedades extremamente complexos de animais selvagens como gorilas, lobos e elefantes, tem mais ou menos erodido a pequena divisão entre humanos e não humanos (WOLFE, 2003b, p. ix) ${ }^{1}$.

Os direitos dos animais surgem como campo que abrange essas considerações e que também serve de horizonte para a composição de demandas, muito embora traga consigo uma série de limitações pontuais. A primeira e mais importante reside na dependência dos proponentes dos direitos dos animais a um pano de fundo marcado por filosofias que são essencialmente humanista, operando através da distinção humano/não-animal. A alteridade radical que se abre no encontro com o animal corre o risco de ser apagada e reinscrita no horizonte das filosofias políticas liberais (DERRIDA, 2002, p. 372; SIEGEL, 2011, p. 233 e ss). 
Um problema significativo neste ponto consiste no esvaziamento essencial da categoria de sujeito, no sentido de que ele não mais se encontra ancorado em alguma determinação específica (o gênero, a etnia ou mesmo o pertencimento a certa espécie), não atua sobre as várias desigualdades materiais na qual esses sujeitos estão inseridos. Trata-se de uma situação paralela àquela do jusnaturalismo e também dos direitos humanos: a universalidade do sujeito, postulada em termos de igualdade e liberdade, é negada às diversas comunidades particulares nas quais se encontram esses sujeitos. Em síntese, o esvaziamento presente na forma do sujeito moderno, compreendido como a sua desvinculação a qualquer tipo de determinação essencial, não previne o surgimento e a manutenção das múltiplas assimetrias que se fazem presentes na esfera social em que esses indivíduos se encontram inseridos.

Em suas considerações sobre a temática, Peter Fitzpatrick observa como o sujeito de direito e a subjetividade jurídica moderna se estabelecem como mitos voltados para a sustentação da identidade do direito (FITZPATRICK, 1992, p. 118 e ss) . Aqui se faz presente um problema teórico considerável: a fundamentação da mitologia moderna ainda repousaria no indivíduo mesmo considerando que a Modernidade encerra o elo com o transcendente, especialmente Deus, subordinando-o ao reino finito do soberano. Mas como essa passagem pôde ter sido mantida?

A passagem rumo a uma concepção finita, logo, contingente, do sujeito soberano reflete o corte proporcionado, no lluminismo, pelo surgimento das ciências humanas. O sujeito soberano anterior a este corte era, por assim dizer, a representação da ordem no mundo, trazendo consigo uma confluência entre representação e existência. Encerra-se o mito: o sujeito soberano é onisciente, tudo pode conhecer, configurando como pressuposto necessário para o conhecimento das leis universais constitutivas da realidade. A cisão entre o humano e o nãohumano, neste ponto, é significativa: ciência implica no controle prático e estratégico da natureza em prol dos benefícios e conveniências humanas. O outro do humano existe em função do humano. Derrida pontua bem como o termo mais amplo, 'o animal', acaba sendo frequentemente empregado para assimilar toda a diversidade do não-humano a uma unidade geral e indiferenciada (DERRIDA, 2002, p. 64 e ss)

A ascensão das ciências humanas põe fim ao mito, inscrevendo o sujeito soberano no rol de outros entes mundanos: o privilégio ontológico rompeu-se com o encerramento da narrativa mítica. Assim como qualquer outro ente, o ser humano é mais um objeto da natureza, passível mesmo de ser apagado dos vestígios da história quando chegar o seu fim. Isso, porém, não impede que a relação de controle e subjugação da natureza seja reconfigurada em uma outra forma. Ao mesmo tempo em que põe fim a uma dada configuração do mito, a ciência reforça os pressupostos metafísicos pelos quais a natureza persiste como objeto, estabelecendo uma outra narrativa mítica. Nesta narrativa, a possibilidade de transcendência da história e de sua finitude reside no conhecimento das leis universais.

Se, por um lado, nada foge ao escrutínio da razão, por outro o processo de dominação através do conhecimento é marcado por uma circularidade problemática, sem um ponto de descanso factível: o anseio pelo esclarecimento condena o saber de ontem a retornar como mito, e assim por diante. Em clara alusão à 'Dialética do Esclarecimento' de Theodor W. Adorno e Max Horkheimer, Fitzpatrick observa:

A designação mítica do homem no conhecimento científico e histórico proporciona à capacidade do homem transcender e dominar o conhecimento, inclusive o conhecimento de si mesmo. O sujeito é criado e formado através de um processo crescente de autodescoberta e autocontrole, processo este que é miticamente apresentado em variedades de progressão. O que o sujeito precisa ainda conquistar se

78 | Revista Brasileira de Direito Animal, e -issn: 2317-4552, Salvador, volume 15, n. 02, p.74-91, Mai - Ago 2020 
torna a promessa de um preenchimento. Inexistem estações de parada neste caminho da progressão em que a força criativa do sujeito poderia descansar ao se satisfazer com algum tipo de conquista determinada (FITZPATRICK, 1992, p. 119) ${ }^{2}$.

O sujeito cognoscente se converte na principal referência e justificação para um tipo de pensamento que mais se caracteriza por uma antropotécnica, uma tecnologia voltada para o controle e disposição de seres humanos e coisas, que aqui se confundem: ambos são objetos para um fim. A reflexão sobre este fim, porém, não é mais um meio, não pode ser mensurada ou empiricamente comprovada, assim como as tradicionais questões herdadas pela tradição filosófica. O resultado é que a reflexão sobre os meios, enquanto questão que propõe um convite a uma reflexão metafísica, será deixada de lado: ela não se adequa à calculabilidade e à metrificação que, aos poucos, passam a representar a racionalidade científica.

Seguindo de perto as indagações de Foucault sobre esta temática, mais especificamente aquelas encontradas em 'As Palavras e as Coisas' e 'A Ordem do Discurso', Fizpatrick observa que a tensão entre o sujeito soberano que busca transcender a finitude e um sujeito que agora, pela ascensão das ciências humanas, descobre-se finito, demarca uma concepção de subjetividade que, por si só, vai integrar esses dois aspectos. No período dessas duas obras, Foucault não só observara que o discurso criava os próprios objetos dos quais falava ao invés de representá-los enquanto entidades exteriores, como também essa força que viabiliza tais criações: o poder.

Então, considerando que o discurso cria o objeto e o campo a que ele mesmo se refere, o sujeito moderno é ele mesmo um efeito das práticas e tecnologias difusas em esferas variadas do social. A subjetividade jurídica da qual este artigo discorreu há pouco é, por sua vez, uma construção dos discursos que organizam o poder jurídico. Se é pensada em termos abstratos, a exemplo de ser humano ou natureza humana, como nas versões tradicionais do jusnaturalismo, assim ocorre em função dos discursos, não de sua transcendência.

Para esta pesquisa, porém, existe um ponto ainda mais relevante nessas considerações foucaultianas: a subjetividade como efeito de tecnologias as quais se recorre para se tornar sujeito, trabalhando diferentes modos de resistência e ação (HARRER, 2005, p. 76 e ss). Um famoso exemplo são os estudos tardios de Foucault sobre o helenismo e as suas várias filosofias voltadas para o bem-viver e para a superação das várias mazelas humanas. Abordando a subjetividade em termos de processos, ao mesmo tempo em que objeto discursivamente construído, permite, por sua vez, colocar em evidência não somente as condições discursivas que a tornam possível, como o que pode ultrapassar essas condições.

No que concerne à problemática dos direitos dos animais, a abordagem foucaultiana resgatada por Fitzpatrick traz uma implicação relevante: a subjetividade como construção discursiva, ou seja, como efeitos de práticas que constituídas através de relações de poder multilaterais e contingentes. A emergência da subjetividade moderna não só põe em evidência as condições que lhe possibilitaram a existência, como também se abre espaço para o seu deslocamento nas estruturas discursivas nas quais ela se encontra situada: o corte que distingue 0 humano dos outros animais pode ser confrontado e redefinido.

Várias são as implicações que a animalidade traz para a manutenção e reprodução de certos parâmetros da chamada condição humana. Critérios como o de senciência podem servir como referência para uma redefinição nas maneiras pelas quais um grupo expressivo de animais são tratados, mas a separação humano/animal não necessariamente é confrontada neste processo - e este é o primeiro ponto a ser confrontado.

Discorrendo sobre os direitos humanos, Costas Douzinas lembra que as razões pelas quais um grupo de direitos feito especificamente para os seres humanos em detrimento dos outros entes não é, a princípio, tão evidente quanto parecem ser. As pretensões universalistas dos 
direitos naturais esbarram na historicidade que vai constituir o contexto das suas enunciações. $\mathrm{O}$ que é concebido como universal - a essência do humano - mostra-se mais particular e impreciso do que, a princípio, parece ser. Ele descreve esse impasse:

A ideia de uma humanitas ou do ser humano não é autodefinidora ou autodeterminadora. O direito natural clássico e as definições modernas iniciais extraíram suas forças normativas das pretensões acerca do que se conta como caracteristicamente humano e derivaram as suas prescrições da natureza e da necessidade do "humano". Mas suas definições do "humano" diferiam bastante conforme a época, o lugar, ou a escola de pensamento e, da mesma maneira, a posição da humanidade no mundo e as suas relações com os outros seres têm variado bastante em todas as épocas (DOUZINAS, 2000, p. 184)

As diferentes formas de relação com os outros seres, incluindo o ecossistema de maneira mais ampla, contribuem também para a própria definição do que é o ser humano e quais são os aspectos centrais dessa caracterização. Reitera-se mais uma vez não só a historicidade da subjetividade, como também a maneira pela qual a sua existência - e, em certo sentido, também permanência - vai depender da caracterização do seu entorno, ou seja, do que transcende o humano.

Do ponto de vista estritamente jurídico, a caracterização de uma subjetividade nãohumana não se resolve através de normas jurídicas positivas que passam a dotar certos entes, como os animais sencientes, de personalidade e/ou de alguma forma de proteção. Neste caso, embora haja um aumento significativo na proteção estendida aos animais, a referência central, subjacente à própria norma, permanece sendo o ser humano. Permanece uma ontologia jurídica na qual o ser humano não só possui prioridade, como também é o eixo central sob o qual os outros entes adquirem sentido, posição e importância. Seria mesmo viável pensar uma configuração ontológica diversa deste modelo?

Uma vez considerada a historicidade da subjetividade e a maneira pela qual as suas fronteiras constitutivas revelaram-se contingentes, instáveis, a subversão dessa concepção de subjetividade e da ontologia que Ihe é subjacente mostra-se como uma alternativa razoável. A dificuldade maior é a realização desse esboço quando tradicionalmente a normatividade jurídica tivera como referência o humano.

Por mais difícil que seja, o teórico do direito não pode deixar de se furtar a ponderar, no mínimo, certas considerações advindas das transformações históricas do próprio direito. A escravidão assinala bem a relevância de uma investigação ontológica acerca da distinção entre o humano/não-humano. Os ordenamentos jurídicos que traziam consigo a escravidão convertiam um dado biológico - o escravo é biologicamente um ser humano - em condição jurídica - o escravo é juridicamente uma coisa, propriedade.

Isso reitera o que Douzinas mencionara acerca do humano: essa qualificação não é autoevidente, nem repousa sob critérios invariáveis e/ou apodíticos, muito embora a utilização teórica - ou mesmo dogmática - do qualificativo transmita um grau de certeza similar. Os elementos apontados pelo humanismo ocidental como distintivos dos seres humanos, de fato, caracterizam uma abstração universal cujas ressonâncias nos vários contextos específicos permanece ausente. Não apenas os escravos, mas mulheres, homossexuais, refugiados, indígenas, todos de alguma maneira tiveram certas prerrogativas jurídicas negadas ao serem tratados desigualmente. A igualdade universal, concebida como inata aos seres humanos, permanecera como construção abstrata apta a legitimar configurações políticas que beneficiavam um segmento muito específico da humanidade (DOUZINAS, 2000, p. 187 e ss). 
Seguindo essa linha de reflexão, os militantes dos direitos dos animais, especialmente aqueles que colocam em questão as práticas de vivissecação, problematizaram a distinção entre humano/animal em termos políticos. Douzinas destaca duas orientações que trazem implicações ontológicas distintas. Na primeira delas, o que se pretende estrategicamente consiste em uma oscilação progressiva da barra que separa o humano e o animal em favor daqueles que trazem consigo mais traços associados aos humanoides, como os gorilas. As espécies são reorganizadas em função de sua proximidade com o humano, sendo esta proximidade a justificação para maiores formas de proteção. Como dito em outro momento, o humano como referência central é mantido.

A segunda orientação, por sua vez, confronta a centralidade do humano, reinserindo-o em um panorama no qual ele não dispõe de qualquer privilégio, sendo apenas mais uma espécie no horizonte mais abrangente do cosmos. Por essa razão pode-se qualificar essa ontologia de plana. Transpor essa premissa para uma ontologia jurídica exigiria repensar radicalmente o sentido da animalidade nas várias formas de relações humanas. Tomando como base essa concepção de ontologia, a representação jurídica, assim como ocorre com as organizações através da pessoa jurídica, pode viabilizar o exercício de direitos e demais prerrogativas jurídicas a entes nãohumanos. Trata-se de um ponto há muito discutido entre teóricos do direito no que se refere à capacidade jurídica. Douzinas destaca esse ponto:

Empresas e outras pessoas jurídicas não-humanas possuíram direitos subjetivos durante séculos, evidentemente. Christopher Stone, um professor de direito norte-americano, tem sustentado que as árvores, os parques e outros objetos naturais também devem ter direitos, e um autor francês tem pleiteado para as zonas de cinturão verdes se convertam em sujeitos de direitos com a prerrogativa de irem a corte, através de seus representantes, para irem às cortes para protegerem os seus ecossistemas de intrusões (DOUZINAS, 2000, p. 185) ${ }^{4}$.

Pensar uma personalidade jurídica não-humana implica em considerar interesses que, embora necessariamente representados por humanos, extrapolam qualquer noção utilitária dos seres humanos. Significa, dentre outros pontos, encarar animais e parques naturais para além de interesses exteriores aos mesmos, incluindo a preservação de espécies, mercadorias, experimentos, dentre outros. O cerne decisivo dos direitos dos animais, o seu principal problema, é a humanização que the é subjacente: humanizar os animais significa inseri-los em um horizonte de significação e de utilidade centrado nas necessidades humanas. Um tratamento humano, no sentido de respeitar a dignidade e a integridade física dos animais, por exemplo, será aquele que for mais conveniente para o bem-estar, físico e psíquico, dos seres humanos.

Um dos aspectos relevantes de se colocar uma subjetividade não-humana (ou desumanizada) residiria em abandonar a valoração extrínseca dos outros entes - só valem enquanto satisfazem necessidades e interesses humanos - por uma forma de valoração intrínseca, que reconheça e acolha os entes não-humanos como em si mesmos dignos, independentemente da maneira pela qual satisfazem - ou não - as necessidades e convenções humanas. Esse talvez seja o ponto mais importante significativo uma vez adotado como ponto de partida uma ontologia plana: o reconhecimento de uma alteridade radical que impeça a subjugação de um polo pelo outro.

Uma outra concepção de desumanização, sem dúvida mais usual, surge como risco e complicador: a desumanização como anulação do jurídico. Neste ponto, a desumanização representaria a exclusão simbólica de um domínio normativo, perceptível em campos de concentração, genocídios, dentre outras situações. O paradigma da exceção visto no campo de 
concentração de Auschwitz e na prisão de Guantánamo traduziriam o oposto exato da concepção de desumanização que este trabalho entende como subjetividade desumanizada: o que se tem, neste ponto, é um vazio normativo que torna completamente disponível os entes. Essa ideia de vazio normativo e desumanização traz sérias considerações para os direitos dos animais e a subjetividade jurídica de um modo geral - e mais adiante algumas delas serão elencadas.

3 Extemporaneidade e subjetividade jurídica desumanizada: o animal para além da racionalidade jurídica operacional

$\mathrm{Na}$ linha de argumentação proposta por esta pesquisa, falar em extemporaneidade significa cogitar um deslocamento temporal no qual um conceito - o de subjetividade - não encontra uma conformação com as premissas teóricas e institucionais vigentes. É nesse panorama em que as configurações atuais são desafiadas através de gestos e invenções teóricas que o extemporâneo é pensado. Se uma subjetividade jurídica desumanizada se mostra inadequada ao se tomar como padrão as concepções atuais em torno da personalidade jurídica, é essa inadequação mesma que acusa a extemporaneidade como algo que pode vir a ser, mas que ainda não encontram as condições pelas quais pode se atualizar seja nas construções doutrinárias, seja nos conteúdos normativos que integram o direito positivo.

Pensar essa extemporaneidade envolve também contemplar as condições pelas quais o deslocamento - ou os vários deslocamentos - são mantidos. No que se refere aos direitos humanos, tais condições não se referem à subjetividade, mas à sua ausência no duplo sentido de despersonalização e objetificação. Em outras palavras, o animal surge como ente, objeto, a ser manipulado e inserido de maneira distinta com base no tipo de relação observada: alimento, pet, segurança, objetos desportivos, objeto de caça, objeto de experimentos, apenas para mencionar algumas das mais recorrentes.

Essa disposição instrumental, cuja articulação teórica remete tanto às reflexões de Adorno/Horkheimer quanto as de Heidegger, inscreve-se na produção normativa e dinâmica institucional dos ordenamentos jurídicos através do elo formado entre os animais e os que são considerados como pessoas na forma da lei. Wolfe observa:

Animais são coisas e não pessoas sob a lei dos Estados Unidos - coisas que podem ou não possuir status legal a depender de estarem elas em uma relação de propriedade com alguma entidade designada como "pessoa", fazendo com que deste modo ela possua interesse jurídico e, desta maneira, consiga argumentar em prol do animal em questão (WOLFE, 2013, p. 12)

Richard Epstein concorda com a manutenção do status jurídico de propriedade para os animais. Um dos eixos de justificação para uma abordagem instrumental em torno dos animais é a que se segue: a integridade dos animais deve ser preservada, inclusive reduzindo-lhes o sofrimento, desde que não comprometa os ganhos e os avanços da humanidade (EPSTEIN, 2004, p. 143 e ss). Se a cura para a AIDS depender de experiências dolorosas e letais em chimpanzés e gorilas, para Epstein esse é o preço a ser pago para o avanço no combate à doença. A ideia de que a espécie humana progressivamente se distanciou do mundo natural do qual emergiu, e de que talvez esse seja mesmo o seu desejo mais profundo, é sustentada por Epstein sem maiores considerações analíticas: o antropocentrismo surge como um destino amparado respaldado por uma racionalidade estritamente econômica. 
Para além dessas considerações, Epstein sustenta, os direitos subjetivos foram desenvolvidos tendo como base as necessidades e os interesses dos seres humanos, sendo por isso um instrumento inadequado para dar forma e expressão aos interesses dos animais. Considerá-los propriedade permite que a defesa das suas prerrogativas por meio das partes interessadas, mas não muito mais além disso.

Novamente, neste ponto, a desumanização não se estabelece em função da alteridade subjacente à divisão entre humano/animal, mas para circunscrever o animal dentro de uma lógica jurídico-política estritamente humana. Trata-se do contrário da extemporaneidade associada a uma subjetividade jurídica porvir: o que se pretende é justificar o presente de coisas em detrimento de fornecer elementos conceituais aptos à sua transformação. O pragmatismo em questão confunde-se com considerações rasas em torno das implicações práticas de opções conflitantes, perdendo com isso a maneira como chegava a lidar filosoficamente com a experimentação e com as possibilidades latentes inscritas nas diversas conjunturas sociais.

Ainda que se desconsidere a ausência de uma problematização mais significativa do antropocentrismo subjacente à linha de argumentação adotada por Epstein, a mesma soa frágil e desconcertante diante das investigações sobre os matadouros nos Estados Unidos. A presença do suporte legislativo associado à regulamentação dos animais de cativeiro tem se mostrado mínima e de discutível implementação:

Conforme as estatísticas do departamento americano de agricultura, no ano passado, 2007, mais de nove bilhões de animais foram mortos nos Estados Unidos para consumo alimentício - a vasta maioria deles criados em operações de confinamento animal (OCA) ou "cativeiros" - duplique o número em 1980. Essas cifras não incluem a morte de peixes, crustáceos e outros animais criados em cativeiro, nem incluí os equineos. A comissão nacional sobre a criação industrial de animais em cativeiro um projeto da Pew Charitable Trust e da escola de saúde pública da John Hopkins Bloomberg - encerrou o seu relatório final de 2006 alegando que "atualmente, a regulamentação federal do tratamento dos animais de cativeiro é mínima", havendo duas leis aprovadas em 1873 e 1958 (WOLFE, 2013, p. 11-12).

O espaço do cativeiro talvez seja o maior desafio das leis voltadas à proteção dos animais. São nesses espaços em que o sofrimento e a privação atingem o seu limite, onde bilhões são mortos nas condições mais abjetas que também se fará presente uma indiferença persistente, quando não uma dificuldade em se submeter aos imperativos regulamentares das legislações disponíveis. Isso decorre da própria mercantilização que subjaz aos animais que integram esse espaço: na medida em que são propriedades, encontram-se também livremente disponíveis. 0 cativeiro é também um espaço ontológico no qual a vida se apresenta, antes de mais nada, como mercadoria a ser administrada.

Os paralelos com os campos de concentração e os regimes de escravidão, neste pormenor, são significativos: nos três eixos - matadouros e cativeiros, campos de concentração e regimes de escravidão - a dessubjetivação leva a uma disponibilidade fatal do ente diante daquele que lhe detém a posse. Nesses espaços, a preocupação decisiva refere-se à gestão da vida em termos de manipulá-la para dela se extraia o máximo em termos de recursos e benefícios: a força física e reprodutiva dos escravos, bem como o seu valor de troca; o campo de concentração como centro de produção e exploração do trabalho forçado; os matadouros e cativeiros como espaço de produção de riquezas através da gestão da vida e da morte dos animais. 
Essa lógica se estende a todo e qualquer contexto nos quais entes viventes são mercantilizados: o mercado de raças caninas, por exemplo, também depende da gestação cuidadosa dos espécimes para que possam gerar descendentes que atendam aos padrões dos consumidores. Qualquer anomalia ou traço que proporcionem quaisquer formas de prejuízo econômico pode implicar na morte, concebida como sacrifício voltado à redução de eventuais prejuízos.

Mais uma vez a subsunção do animal à ideia de propriedade, anulando qualquer forma de personalidade, ainda que restrita, dificulta de maneira significativa a sua proteção jurídica através de qualquer lei que vise a proteger o seu bem-estar. Isso porque este 'bem-estar' existe e adquire sentido somente a partir da configuração biopolítica na qual o ente se encontra inscrito. Gestão e produção encontram-se entrelaçadas neste ponto.

Se Foucault expôs a subjetividade moderna como produto contingente de tecnologias administrativas difusas, ponto semelhante pode ser estendido aos vários regimes que circunscrevem os animais como mercadorias e objetos a serem geridos para fins específicos. A gestão da vida, que na modernidade será posta em evidência mediante o desenvolvimento das ciências que tomam o ser humano como objetivo, a gestão da vida animal adquire estratégias e tecnologias específicas em conformidade com a utilidade, para recorrermos a um termo valioso a Richard Epstein e também Richard Posner (POSNER, 2004, p. 51 e ss).

Em síntese, a dessubjetivação remete à completa disponibilidade do animal dentro de um panorama (framework) utilitário, produzindo várias implicações jurídicas relevantes, o que inclui a indiferença - e até aceitação - do sofrimento e da morte de vários animais nas diversas relações estabelecidas com os seres humanos. Alternativas para este impasse, através da redefinição da subjetividade jurídica, proporcionam as mais diversas teorizações. Uma delas, que sem dúvida traz consigo certo grau de extemporaneidade, consistiria em estender os direitos e garantias presentes nos direitos humanos aos animais, ou ao menos adotá-lo como principal referência. Uma outra reside no deslocamento de uma concepção antropocêntrica para uma biocêntrica, como os proponentes da ecologia profunda (deep ecology) há algum tempo defendem (WOLFE, 2003a, p. 24 e ss).

Derrida tece uma observação bastante significativa para este trabalho: a inserção dos animais como sujeitos de direito, a partir do panorama jurídico existente, reafirma uma certa concepção de sujeito humano que fora a responsável pelos piores e mais recorrentes abusos de seres não-humanos (DERRIDA; ROUDINESCO, 2004, p. 65 e ss; DERRIDA, 2007, p. 34 e ss). Significaria, dentre outras questões, reafirmar a subjetividade como elemento indispensável para o controle e a subjugação dos entes a uma lógica muitas vezes implícita, mas certamente presente, de gestão dos benefícios (WOLFE, 2013, p. 16 e ss). A força simbólica e mesmo normativa dos direitos humanos não fora suficiente para proteger e/ou transformar as circunstâncias recentes das mulheres no Afeganistão, os conflitos civis em Ruanda, Serra Leoa e atualmente no Sudão. Para além disso, os proponentes dos direitos dos animais dificilmente sustentam uma equiparação de direitos entre humanos e não-humanos (WOLFE, 2003a, p. 34)

A questão articulada por Derrida reside em pensar a problemática do animal para além do pano de fundo jurídico no qual os ativistas normalmente tendem a inscrever a temática sem, contudo, exclui-la do horizonte mais amplo do jurídico. Semelhante abordagem implica em um trabalho teórico mais radical e abrangente uma vez que será o sentido histórico do jurídico que está sendo posto em questão: se os animais não podem ser considerados cidadãos e detentores de direitos políticos, por isso mesmo não seria o caso de excluí-los completamente de qualquer dimensão do jurídico. É preciso repensar o sentido dos direitos e do que significa ser um portador de direitos (DERRIDA; ROUDINESCO, 2004, p. 74 e ss).

Ao se falar em uma subjetividade jurídica extemporânea e na desumanização do animal, o objetivo da pesquisa reside em trazer à tona os limites e possibilidades inscritos no conceito de

84 | Revista Brasileira de Direito Animal, e -issn: 2317-4552, Salvador, volume 15, n. 02, p.74-91, Mai - Ago 2020 
sujeito de direito ao ser confrontado com a diferença radical - ou alteridade - proporcionada pelo encontro com o animal. É nesse encontro em que ética, justiça e direito tendem a se dissociar (LAWLOR, 2007, p. 10 e ss). Isso porque, desde os seus primórdios no direito romano, a reflexão jurídica tratou de elaborar um sistema normativo voltado ao esclarecimento de capacidades e de prerrogativas: é crucial determinar a quem compete os direitos e quais pessoas podem exercê-lo em proveito próprio ou de terceiros. Se o direito se define pelo cálculo e fechamento, a justiça se coloca como abertura e o incalculável (DERRIDA, 2007, p. 30 e ss)

A diferença entre os entes existe em função das determinações estabelecidas pelas regras: as distinções adquirem sentido em função do sistema normativo no qual se encontram inseridas. Neste contexto, as diferenças são - e precisam ser - operacionalizáveis. A relação ética, no entanto, ancora-se na compaixão, na responsabilidade, e na demanda infinita e incalculável (DERRIDA, 2007, p. 41 e ss). A passagem do jurídico ao ético não decorre apenas de uma inadequação da forma jurídica para lidar com um certo conjunto de questões, mas da possibilidade de distorção e trivialização das questões. Em todo o caso, ela abre o jurídico para reestruturações imprevisíveis que permitem colocar em xeque as suas operações conceituais internas: o outro, o fora, nunca pode ser exaurido pelo sistema que the observa (WOLFE, 1998, p. 118 e ss; DERRIDA, 2007, p. 54 e ss).

Direitos proporcionam espaços nos quais as proteções oferecidas podem ser suspensas ou manipuladas para a preservação de objetivos. Ainda se mostram persistentes as defesas da tortura como prática adequada diante de supostas ameaças terroristas e/ou políticas: o mesmo cálculo que determina os direitos e garantias individuais é também aquele que os suspendem. $O$ mesmo raciocínio, em parte, vai se estender ao atual tratamento jurídico dos animais.

Pensar radicalmente uma subjetividade jurídica extemporânea, especialmente no tocante à temática dos animais, envolve interrogar a base ontológica na qual não somente o sujeito de direito se funda, como também mantém a divisão entre formas de vida que devem ser protegidas daquelas que não necessitam. Se pensar uma subjetividade jurídica não-humana e desarticulada de uma lógica específica da personalidade jurídica como detentora de direitos é extemporânea, isso significa também que ela ainda não encontrou os pressupostos ontológicos que the permitiriam ser atualizada. Indagar por esses pressupostos é o próximo passo teórico e também o objeto da próxima seção.

\section{Redefinindo a questão: o animal através da subjetividade jurídica extemporânea}

Um dos aspectos mais persistentes na ontologia do direito moderno reside em seu individualismo, ou, de maneira mais precisa, na maneira como a vida é concebida primariamente através da relação entre indivíduos ao invés da interdependência das pessoas. A subjetividade é concebida também em termos de agência: a busca pelo reconhecimento das necessidades do outro ao mesmo tempo em que se luta por ser reconhecido. Nesta conjuntura, porém, os animais e outros entes não-humanos são deixados de fora uma vez que não se inscrevem - e não podem mesmo se inscrever - na dinâmica do reconhecimento.

Mesmo os estudos culturais (cultural studies) e as mobilizações políticas envolvendo identidades, neste ponto, também se mostram insuficientes para se pensar o tipo de subjetividade jurídica que esta pesquisa almeja considerar. Wolfe sustenta:

O problema com este modo de crítica é que ele frequentemente reinscreve o próprio humanismo que busca desestabilizar, de maneira que o sujeito, embora recentemente "marcado" pela crítica, é também marcado por um repertório familiar, um que vai constituir a própria

85 | Revista Brasileira de Direito Animal, e -issn: 2317-4552, Salvador, volume 15, n. 02, p.74-91, Mai - Ago 2020 
repressão - o que Derrida vai caracterizar como sacrifício em "Eating Well" - da questão do animal e, de maneira mais ampla, do não-humano (WOLFE, 2003b, p. xii) ${ }^{7}$.

O principal ponto para um tratamento analítico mais rigoroso da questão do animal reside em propor uma alternativa ao pluralismo político teoricamente orientado pelo pós-estruturalismo francês e pelos diversos estudos que vão se constituir sob sua influência. Neste ponto, o campo jurídico encontra-se em uma situação curiosa: ele já traz consigo elementos teóricos para a proposição de descrições de suas próprias práticas independentes de qualquer referência aos agentes humanos (MUSSAWIR, 2011, p. 55). O positivismo jurídico, afinal, esvazia o sujeito de direito de qualquer elemento essencial, naturalístico: este será aquilo que o poder soberano, através da produção de normas jurídicas, determinar.

As principais categorias do direito seriam plásticas: possuem uma forma que thes permitem ser operacionalizadas pelos atores jurídicos (legisladores, juízes, advogados, dentre outros), ao mesmo tempo em que possuem conteúdo indeterminado (MUSSAWIR, 2011, p. 55 e ss). Como Niklas Luhmann já observara, o caráter normativo das operações jurídicas não se restringe à produção ou aplicação de uma regra a um fato, mas à reformulação contínua da unidade do sistema (LUHMANN, 1990, p. 230 e ss). Por isso a proteção jurídica às empresas e ao nascituro não leva a qualquer impasse teórico. Outras abordagens teóricas se mostram também fecundas no trato com essa problemática.

A teoria dos sistemas proposta por Luhmann, por exemplo, representa um dos eixos de investigação em que o direito surge como desatrelado de qualquer fundamentação naturalista ou moral (NOBLES; SCHIFF, 2004, p. 5 e ss). Como em Derrida, a insistência na separação entre direito e justiça aqui ressoa também no abismo entre direito e moralidade. A justiça surge como um problema a ser trabalhado pela própria lógica interna e inerente ao sistema jurídico, concebida como autopoiesis pelo teórico social alemão (LUHMANN, 2004, p. 81 e ss). São questões a serem trabalhadas a partir da diferenciação funcional do sistema jurídico, cujo código legal/não-legal é a base de sua manutenção (LUHMANN, 2004, p. 173 e ss).

Embora a abordagem luhmanniana se afaste de qualquer reflexão ontológica, ao menos explicitamente, a maneira como ela tematiza a relação entre a abertura e o fechamento do sistema jurídico é pertinente para se refletir sobre a possibilidade de uma subjetividade jurídica não-humana uma vez que ilustra um dos pontos da relação entre o sistema e o seu meio ambiente, o que lhe é exterior. A exterioridade do sistema, ao mesmo tempo em que confronta e desestabiliza o sistema, também é condição para a sua existência uma vez que será sobre ela que a diferenciação funcional vai ocorrer (LUHMANN, 2004, p. 79 e ss; LUHMANN, 2010, p. 229 e ss). Em síntese, a criação de novos direitos depende da abertura do sistema jurídico ao seu exterior, o meio ambiente, ao mesmo tempo em que responde ao exterior por meio das suas operações específicas. Cary Wolfe comenta:

...Toda vez que o sistema jurídico proporciona novos direitos e deveres, toda vez que ele proporciona "a associação entre humanos e nãohumanos uma voz jurídica", o direito abre a si mesmo para a ecologia mais ampla do seu meio ambiente e as modificações que lá ocorrem. No modelo da teoria dos sistemas, então, nós temos uma imagem do sistema jurídico como simultaneamente aberto e fechado: aberto para o seu meio ambiente, mas respondendo às mudanças nos termos da autorreferência do seu fechamento autopoietico (WOLFE, 2013, p. 89) ${ }^{8}$. 
A emergência dos novos direitos surge nesse limiar entre a estabilidade das operações do sistema fundadas sobre as especificidades de seu próprio código e as "irritações" proporcionadas pelo meio ambiente do sistema jurídico (WOLFE, 1998, p. 66 e ss). Uma das implicações é a de que qualquer referência a uma essência subjacente às contínuas transformações pelas quais passa o sistema jurídico tende a ser deixada de lado: as operações do sistema existem em função de uma lógica autorreferencial de subsistência dissociada de qualquer propósito ou fundamento $a$ priori (PHILIPPOPOULOS-MIHALOPOULOS, 2011, p. 51 e ss).

Situando deste modo o meio ambiente, ele pode ser concebido como um excesso que não pode ser completamente apreendido pelas operações circulares do sistema: no que concerne ao sistema jurídico, por exemplo, os problemas e conflitos não seriam, de fato, produtos do meio ambiente, mas gerados pelas operações do sistema jurídico (LUHMANN, 2004, p. 88 e ss; LUHMANN, 1990, p. 3 e ss). Em síntese, o meio ambiente existe, para o sistema, através das suas descrições desenvolvidas pelo próprio sistema. Sobre esta noção no âmbito da teoria dos sistemas, James MacLean comenta:

.... meio ambiente do sistema não é tanto algo que lhe é sempre externo e que se busca reagir mas algo criado pelo ator através do processamento da informação conforme o seu foco em um trabalho particular através do processo de seleção. Selecionar significa decidir o que é relevante, o que é preciso considerar e o que pode ser deixado de lado. Algo somente se torna objeto de atenção após a seleção ter ocorrido (MACLEAN, 2012, p. 79-80) ${ }^{9}$.

É nesse excesso que vai residir a problemática do animal e da concepção de uma forma de subjetividade que o envolva sem necessariamente subsumi-lo a um pano de fundo jurídico estranho às suas necessidades e especificidades, como de certa forma Epstein pareceu aludir ao postular como inadequada a inserção dos animais como entes dotados de capacidade jurídica. Não é o caso de ignorar o problema, mas de redefinir os seus contornos e termos. A adoção, nesta pesquisa, de uma subjetividade não-humana em detrimento de uma subjetividade animal reitera essa ideia: a questão do animal não reside tanto na proposição de uma equivalência funcional entre humano e não-humano, mas em abrir espaço para um pós-humanismo.

O recorte teórico proposto por essa pesquisa reside, portanto, em questionar o componente individual, humanístico, subjacente à realidade da prática e da teorização jurídica. Trata-se de um recorte porque uma investigação mais abrangente acerca da ontologia jurídica escapa os limites demarcados pela problemática da pesquisa. Mas em que consistiria redefinir os contornos da problemática jurídica do animal?

Primeiro, afastando a inserção da questão em uma estrutura conceitual já definida, transformando as demandas pelos direitos dos animais em mais um clamor por mais direitos e proteções. Parte-se do pressuposto, visto como problemático, de que haveria uma adequação entre animais e outros entes não-humanos com a forma jurídica dos direitos subjetivos. Ainda que o sujeito de direito em si, sob uma perspectiva positivista e/ou sistêmica, não possua qualquer conteúdo essencial, o exercício dos direitos subjetivos pressupõe uma lógica de representação que está intrinsecamente vinculada à agência humana.

Segundo, explorando a virtualidade do sujeito de direito ao invés de sua atualidade, ou seja, de sua forma normativamente disciplinada nos ordenamentos jurídicos vigentes e nas construções teóricas que o representam (MUSSAWIR, 2011, p. 1 e ss). Uma subjetividade jurídica não atualizada e que escapa às determinações conceituais e normativas vigentes mostra-se extemporânea, inoperável e inoperante, mas suficientemente presente para irritar o funcionamento do sistema jurídico, levando-o a produzir novas reações. 
Terceiro, levando a sério a manutenção dinâmica, e um tanto quanto paradoxal, do sistema jurídico, algo bem visto pela teoria dos sistemas (LUHMANN, 2004, p. 423 e ss). Fundamental para os pontos um e dois, trata-se de confrontar as categorias reificadas que se sobrepõem ao devir social subjacente às práticas jurídicas e às questões que nelas são suscitadas. A ontologia jurídica subjacente a um grande grupo de teorias tende a implicitamente preferir - e justificar - a permanência, a continuidade, a persistência em detrimento da inovação, criatividade e mudança (MACLEAN, 2012, p. 172 e ss). Os eventos são "capturados" a partir de uma lógica estabelecida que Ihes retira o contato com o novo. As considerações de Marc Schuilenburg são oportunas:

Em outras palavras, a questão do direito e da ordem é uma questão secundária. Inicialmente existe um processo permanente de criação e invenção. Ordem e estabilidade sempre surgem depois. Elas emergem da dinâmica do social, como um enrijecimento temporário de uma série contínuas de relações que não representam 'coisas', mas eventos que jamais possuem seu sentido final (SCHUILENBURG, 2012, p. 112) ${ }^{10}$.

Tentador e compreensível, portanto, seria conceber os direitos dos animais a partir da lógica estabelecida do direito subjetivo e da representação judicial uma vez que esses são pressupostos básicos que envolvem a compreensão usual do que significa ter e exercer direitos positivados. Confrontar a subjetividade que implicitamente envolve o conceito de direitos subjetivos mostra-se uma tarefa árdua porque exige que se pense algo que se desloque das premissas contemporâneas com as quais se elaboram as descrições sobre o jurídico. Trata-se, porém, de uma perspectiva teórica demasiadamente restritiva: qualquer ente não-humano só poderá ingressar na seara jurídica através de uma mediação ancorada na agência humana. Esses entes serão sempre coadjuvantes no processo de formação e aplicação das normas jurídicas.

Tanto a desconstrução proposta por Derrida quanto a teoria dos sistemas de Luhmann, por exemplo, permitem abrir o sistema jurídico para uma mudança intrínseca sem tomar como referência definitiva os pressupostos teóricos constitutivos das operações do sistema. Neste sentido, conseguem pensar o extemporâneo sem se deixar aprisionar pelo contemporâneo: para a problemática jurídica dos animais, trata-se de um passo decisivo para se pensar novas formas de subjetividade ou mesmo de sentidos associados ao jurídico, tal como Derrida apontara. A discussão, portanto, excede, embora envolva, a criação de novos direitos positivos que visem a proteger as várias formas de integridade que revestem o animal: o que está verdadeiramente em jogo por trás de toda a análise é o sentido e a importância que a animalidade pode vir a ter para o sistema jurídico e quais potencialidades dispõem-se a serem cultivadas.

\section{Conclusão}

A proposta geral do artigo residiu em mostrar que a problemática dos animais, normalmente exposta sob o rótulo de direito dos animais e defendida pelos seus ativistas, demanda uma redefinição radical de certas noções jurídicas ainda muito caras aos teóricos da área, a exemplo de uma subjetividade que se caracteriza na forma de exercer direitos e exigir o cumprimento de direitos. A princípio, o sujeito de direito é um agente e, como tal, restrito ao humano e às suas ficções. Recorrendo aos trabalhos de Costas Douzinas e Peter Fitzpatrick, buscou-se apontar que mesmo as considerações mais sólidas do jusnaturalismo acerca da natureza humana mostram-se contingentes e historicamente dependentes dos seus contextos de enunciação.

88 | Revista Brasileira de Direito Animal, e -issn: 2317-4552, Salvador, volume 15, n. 02, p.74-91, Mai - Ago 2020 
Partindo de algumas considerações suscitadas por Richard Posner e Richard Epstein, para em seguida associá-las a certas considerações de Jacques Derrida, a ideia fora a de mostrar os problemas e limitações de uma abordagem que pretende inserir os entes não-humanos no mesmo arcabouço conceitual que hoje informam a aquisição e o exercício de direitos pelos humanos. Em uma perspectiva como essa, portanto, o problema residiria na aquisição de direitos e formas de representação dos animais ainda ausentes nos ordenamentos jurídicos positivos.

Um dos pontos centrais do artigo fora o de ressaltar que, na verdade, a problemática envolve uma redefinição significativa do próprio sentido do jurídico (o que significa ter e exercer direitos), como também dos pressupostos ontológicos que implicitamente articulam as categorias (a ênfase na permanência e estabilidade em detrimento da mudança e da criatividade). Ambos os eixos se encontram associados: a redefinição profunda do sentido do jurídico exige uma abertura para o novo, ou seja, para aqueles conteúdos que desestabilizam e reorganizam as noções sedimentadas no sistema.

Existem perspectivas teóricas sobre o jurídico, a exemplo da desconstrução de Derrida e a teoria dos sistemas de Niklas Luhmann que, muito embora de maneiras bem distintas e com propósitos diferentes, abrem o sistema o jurídico para um exterior que não pode ser integralmente assimilado de antemão pelo que já se encontra estabelecido. Em todas essas perspectivas, de maneira diversa, um ponto similar é ressaltado: não existe o jurídico sem o seu exterior e, portanto, o exterior também se encontra internalizado pelo jurídico em um processo de autodiferenciação caracterizado pela sua abertura, necessária, perante o seu meio ambiente.

No que se refere à problemática jurídica dos animais, essas perspectivas permitem conceber o desajuste que perpassa um campo de problemas e o repertório conceitual atual insuficiente para lidar com ele, o que este artigo veio a nomear de extemporâneo. Um sujeito de direito extemporâneo é, por definição, uma construção teórica cuja finalidade é marcar, ao invés de resolver, o direcionamento de uma questão. Em síntese, as demandas e os problemas referentes aos direitos dos animais não se limitam à criação de novos direitos positivos, o que em si é oportuno e necessário, exigindo também um olhar teórico que ultrapasse as fronteiras, sempre frágeis e complicadas, entre o humano e o não-humano no panorama mais abrangente das questões jurídicas.

A proposta do artigo, na medida em que amplamente teórica, buscou examinar e ponderar as questões subjacentes à criação e à inserção dos animais no horizonte jurídico ao invés de se preocupar em analisar as atuais disposições normativas, presentes nos ordenamentos jurídicos positivos, sobre o tema. Buscou evitar repensar a questão nos termos e nos limites das categorias jurídicas vigentes. Ao indagar por uma subjetividade extemporânea, a pesquisa voltase para as possibilidades e aberturas diversas que o sistema jurídico traz consigo e que afetam de maneira decisiva a postulação da questão.

Neste sentido, reitera a plasticidade das categorias jurídicas como forma de redefinir a questão dos animais também à luz de modificações específicas na teoria do direito. Por trás do direito dogmático e das normas jurídicas a eles associadas, a teoria do direito fornece o repertório de conceitos fundamentais que compõem, implicitamente e por vezes explicitamente, as narrativas e representações que juristas, sejam eles teóricos ou práticos, fazem o direito e das suas operações. Colocando a subjetividade em termos extemporâneos busca-se também ressaltar o potencial da teoria do direito em realizar redefinições radicais diante de problemas que levam ao limite os seus vocabulários e categorias disponíveis. Certamente, trata-se de uma tarefa muito difícil, mas também é preciso reconhecer que as múltiplas questões referentes aos animais no âmbito jurídico também não podem mais esperar. 


\section{Referências}

DERRIDA, Jacques. Força de Lei. São Paulo: Martins Fontes, 2007. . O Animal que logo sou. São Paulo: Editora Unesp, 2002. . The Animal That Therefore I Am (More to Follow). Critical Inquiry, v. 28, n. 2, 2002, pp.

369-418.

DERRIDA, Jacques; ROUDINESCO, Elisabeth. For What Tomorrow...: A Dialogue. Stanford: Stanford University Press, 2004.

DOUZINAS, Costas. The End of Human Rights: Critical Legal Thought at The Turn of The Century. Oxford: Hart Publishing, 2000.

EPSTEIN, Richard A. Animals as Objects, or Subjects, of Rights. In SUNSTEIN, Cass R.; NUSSBAUM, Martha C. Animal Rights: Current Debates and New Directions. New York: Oxford University Press, 2004, pp. 143-161.

FITZPATRICK, Peter. The Mythology of Modern Law. London: Routledge, 1992.

HARRER, Sebastian. The Theme of Subjectivity in Foucault's Lecture Series L'Herméneutique du Sujet'. Foucault Studies, n. 2, Maio/2005, pp. 75-96.

LAWLOR, Leonard. This is not Sufficient: An Essay on Animality and Human Nature in Derrida. New York: Columbia University Press, 2007.

LUHMANN, Niklas. Essays on Self-Reference. New York: Columbia University Press, 1990. . Law as a Social System. Oxford: Oxford University Press, 2004.

MACLEAN, James. Rethinking Law as Process: Creativity, Novelty, Change. London: Routledge, 2012.

MUSSAWIR, Edward. Jurisdiction in Deleuze: The Expression and Representantion of Law. London: Routledge, 2011.

NOBLES, Richard; SCHIFF, David. Introduction. In: LUHMANN, Niklas. Law as a Social System. Oxford: Oxford University Press, 2004, pp. 1-52.

PHILIPPOPOULOS-MIHALOPOULOS, Andreas. Critical Autopoiesis: The Environment of the Law. In: VRIES, Bald de; FRANCOT, Lyana (orgs). Law's Environment: Critical Legal Perspectives. The Hague, Netherlands: Eleven International Publishing, 2011. pp. 45-62.

POSNER, Richard A. Animal Rights: Legal, Philosophical, and Pragmatic Perspectives. In SUNSTEIN, Cass R.; NUSSBAUM, Martha C. Animal Rights: Current Debates and New Directions. New York: Oxford University Press, 2004, pp. 51-77.

SCHUILENBURG, Marc. Institutions and Interactions: On the Problem of the Molecular and Molar. In: SUTTER, Laurent de; MCGEE, Kyle (orgs). Deleuze and Law. Edinburgh: Edinburgh University Press, 2012. pp. 111-131.

SIEGEL, James. "Tout Autre es Tout Autre". In: BERGER, Anne Emmanuelle; SEGARRA, Marta. Demenageries: Thinking (of) Animals after Derrida. New York: Rodopi, 2001. pp. 213-244.

WOLFE, Cary. Animal Rites: American Culture, the Discourse of Species, and Posthumanist Theory. Chicago: The University of Chicago Press, 2003a.

. Before the Law: Humans and Other Animals in a Biopolitical Frame. Chicago and London: The University of Chicago Press, 2013.

Critical Environments: Postmodern Theory and the Pragmatics of the "Outside". Minneapolis: University of Minnesota Press, 1998.

Introduction. In: WOLFE, Carey. Zoontologies: The Question of the Animal. Minneapolis: University of Minnesota Press, 2003b, pp. ix-xxii. 


\section{Notas de Referência}

${ }^{1}$ No original: "The second factor, of course, is the fact toward which I have already gestured, however briefly: the radically changed place of the animal itself in areas outside the humanities. Indeed, the humanities are, in my view, now struggling to catch up with a radical revaluation of the status of nonhuman animals that has taken place in society at large. A veritable explosion of work in areas such as cognitive ethology and field ecology has called into question our ability to use the old saws of antropocentrism (language, tool use, the inheritance of cultural behaviors, and so on) to separate ourselves once and for all from animals, as experiments in language and cognition with great apes and marine mammals, and field studies of extremely complex social and cultural behaviors in wild animals such as apes, wolves, and elephants, have more or less permanently eroded the tidy divisions between human and nonhuman".

${ }^{2}$ No original: "The mythic designation of man in scientific and historical knowledge provides for man's capacity to transcend and master knowledge, including the knowledge of 'himself'. The subject is created or realized through growing self-discovery and self-mastery, a process mythically presented in varieties of progression. What the subject has yet to attain becomes the promise of fullfilment. There are no way-stations on this path of progression at which the subject's creative force can rest contented in some fixed achievement".

${ }^{3}$ No original: "The idea of humanitas or the human being is not self-defining or self-determining. Classical natural law and early modern definitions of rights drew their normative force from claims about what counts as characteristically human and derived their prescriptions from the nature and needs of "humanness". But their definitions of the "human" differed widely according to age, place and scholl of thought and, similarly, the position of humanity in the world and its relation to other beings has varied enormously in all ages".

${ }^{4}$ No original: "Companies and other non-human legal persons have been given legal rights, of course, for centuries. Christopher Stone, an American law professor, has argued that trees, parks and other natural objects too should be given rights, and a French author has called for turning greenbelt zones into legal subjects with the power to go to court, through representatives, to protect their ecosystem from intrusion".

${ }^{5}$ No original: "Animals are things and not persons under United States law - things that may or may not have legal status depending on whether or not they have a property relation to an entity designated a "person", who thus has a legal interest in, and standing to argue on behalf of, the animal in question".

${ }^{6}$ No original: "According to statistics by the US Department of Agriculture, in the previous year, 2007, about nine billion animals were killed in the United States for food - the vast majority of them raised in Confined Animal Feeding Operations (CAFOs) or "factory farms" - double the number in 1980. This figure does not include the killing of fish, crustaceans, and other farmed animals, nor does it include equines. The National Commission on Industrial Farm Animal Production - a project of the Pew Charitable Trust and the John Hopkins Bloomberg School of Public Health - concluded in its final report of 2006 that "at the present, federal regulation of the treatment of farm animals is minimal", with the two main pieces of legislation having been passed in 1873 and 1958 ".

${ }^{7}$ No original: "The problem with this mode of critique is that if often reinscribes the very humanism it appears to unsettle, so that the subject, while newly "marked" by critique, is marked by means of a very familiar repertoire, one that constitutes its own repression - or what Derrida in "Eating Well" will characterize as a "sacrifice" - of the question of the animal and, more broadly still, of the nonhuman".

${ }^{8}$ No original: “... whenever the law grants new rights and duties, whenever it gives "associations between humans and non-humans a legal voice", the law opens itself to the ecology of its broader environment and the changes taking place there. In the systems theory model, then, we have a picture of the legal system as both open and closed: open to its environment but responding to changes in it in terms of the autopoietic closure of its own self-reference".

${ }^{9}$ No original: “...a system's environment is not so much something already external to be reacted to but it is created by the actor through the processing of information according to her focus on a particular task, by the process of selection. Selecting has to do with deciding what is relevant, what to deal with and what to leave alone. Something only become the object of attention after this selection has occurred".

${ }^{10}$ No original: "In other words, the issue of law and order is a secondary issue. Initially there is the permanent process of creation and invention. Order and stability always follow later. They emerge from the dynamics within the social, as a temporary congealing point of continually branching series of relations that do not represent 'things', but events that never obtain their final meaning". 